\title{
Groucho acts as a corepressor for a subset of negative regulators, including Hairy and Engrailed
}

\author{
Gerardo Jiménez, ${ }^{1}$ Ze'ev Paroush, $^{2}$ and David Ish-Horowicz ${ }^{1,3}$ \\ ${ }^{1}$ Imperial Cancer Research Fund (ICRF), London WC2A 3PX, England; ${ }^{2}$ Department of Biochemistry, Hadassah M edical \\ School, The Hebrew University, Jerusalem 91120, Israel
}

\begin{abstract}
Relatively little is known about the molecular mechanisms involved in transcriptional repression, despite its importance in development and differentiation. Recent evidence suggests that some transcriptional repressors act by way of adaptor molecules known as corepressors. Here, we use in vivo functional assays to test whether different repressor activities are mediated by the Groucho (Gro) corepressor in the D rosophila embryo. Previously, Gro was proposed to mediate repression by the Hairy-related family of basic helix-loop-helix proteins. Our results indicate not only that repression by Hairy requires Gro, but that a repressor domain from the Engrailed (En) homeodomain protein is also Gro dependent. The latter result correlates with an ability of this En domain to bind to Gro in vitro. In contrast, repressor regions from the Even-skipped, Snail, Krüppel, and Knirps transcription factors are effective in the absence of Gro. These results show that Gro is not generally required for repression, but acts as a specific corepressor for a fraction of negative regulators, including Hairy and En.
\end{abstract}

[Key Words: Groucho; corepressor; repression; Hairy; Engrailed; Drosophila]

Received June 20, 1997; revised version accepted September 18, 1997.

Transcriptional repression plays a key role in establishing precise patterns of gene expression during development (Gray and Levine 1996b; Ip and Hemavathy 1997). For example, most transcriptional regulators that control pattern formation in the early Drosophila embryo behave as repressors. Although mechanisms of repression are less well understood than those leading to gene activation, two major modes of repression have been identified (Cowell 1994; Johnson 1995; Hanna-Rose and Hansen 1996). In one case, repressors function by interfering passively with binding of activators to target promoters. This can involve the formation of repressor/activator complexes that are unable to bind DN A, or the occlusion of activator DN A-binding sites by binding of the repressor to overlapping target sequences. A second class of repressor binds to specific DNA sites, and blocks transcription actively through protein-protein interactions with other promoter factors.

Like transcriptional activators, "active" repressors of the second class appear to have a modular nature. In addition to a DNA-binding domain, they include discrete protein domains that can impose repressor activity on heterologous DNA-binding regions. Repressor modules can share certain structural similarities, including a preponderance of alanine residues [e.g., those from the

${ }^{3}$ Corresponding author.

E-MAIL d.horowicz@icrficnet.uk; FAX +44-171-269-3417.
Drosophila Engrailed (En), Even-skipped (Eve), and Krüppel (Kr) proteins; Han and Manley 1993a,b; Licht et al. 1994; for review, see Hanna-Rose and Hansen 1996], but the role of such structural features is not understood. Some repressor domains are likely to establish di rect interactions with components of the transcriptional machinery (e.g., those from Eve and Kr; Sauer et al. 1995; Um et al. 1995) or with promoter-bound activator factors. However, others probably function by recruiting accessory proteins ("corepressors") that themselves effect repression.

The best-characterized example of corepression involves a complex formed by the yeast proteins TUP1 and SSN 6, which are required for repression by the $\alpha 2$ homeodomain protein (Keleher et al. 1992). These two proteins do not bind inherently to DNA, but appear to be recruited to promoters through interactions with $\alpha 2$. Once at the promoter, the TUP1/SSN 6 complex mediates repression, possibly by binding downstream proteins such as basal transcription factors or histones (Edmondson et al. 1996). Other repressor-corepressor models include Mad-mSin3 and nuclear hormone receptor$\mathrm{N}-\mathrm{CoR} / \mathrm{mSin} 3$ associations in mammalian cells (Horlein et al. 1995; Kurokawa et al. 1995; Alland et al. 1997; Heinzel et al. 1997).

The Drosophila Groucho (Gro) protein, a maternally contributed nuclear factor (Hartley et al . 1988; Delidakis et al. 1991), is a putative corepressor (Paroush et al. 1994; 
Fisher et al. 1996). Gro lacks a recognizable DN A-binding domain but, like TUP1, contains repeated WD motifs that are believed to mediate protein-protein recognition (for review, see Neer et al. 1994). Previously, we have proposed that Gro functions as a corepressor for the Hairy family of basic helix-loop-helix (bHLH) transcription factors (Paroush et al. 1994), which includes the Hairy, Deadpan (Dpn), and Enhancer of split [E(spl)] proteins that act in segmentation, sex determination, and neurogenesis, respectively (Klämbt et al. 1989; Rushlow et al. 1989; Bier et al. 1992; Delidakis and ArtavanisTsakonas 1992; Knust et al. 1992; Schrons et al. 1992; Y ounger-Shepherd et al. 1992). The Hairy/Gro corepression model is supported by the finding that Gro binds in yeast and in vitro to a conserved carboxy-terminal tetrapeptide (WRPW) present in the above bHLH proteins, which functions as an active repressor domain in cultured cells (Paroush et al. 1994; Fisher et al. 1996). In addition, Gro activity is required maternal ly for the processes regulated by the Hairy-related proteins. In embryos lacking maternal gro (hereafter referred to as gro mutant embryos), hairy (h) expression overlaps that of one of its targets of repression, fushi tarazu (ftz) (Carroll and Scott 1986; Howard and Ingham 1986; Ish-Horowicz and Pinchin 1987; Paroush et al. 1994). Also, the femalespecific gene Sex-lethal $(\mathrm{SxI})$, which is normally repressed by Dpn, is expressed ectopically in male embryos (Younger-Shepherd et al. 1992; Paroush et al. 1994). Finally, the mutant embryos show neural hyperplasia attributable to excessive sel ection of neural precursors, a process that is normal ly inhibited by $\mathrm{E}(\mathrm{spl}$ ) (Delidakis et al. 1991; Schrons et al. 1992; Paroush et al. 1994).

Despite the emergence of an increasing number of corepression models, limited information is still available on the specificity of corepressors, that is, whether they mediate the activity of uni que repressors/ repressor families, or whether they serve as common effectors for different classes of repressors (or even all or most repressors). In the case of TUP1/SSN 6, a number of studies suggest that this complex mediates repression by several classes of repressors (Keleher et al. 1992; Treitel and Carlson 1995). In this paper, we analyze the specificity of corepression in a higher eukaryote by examining whether different repressor activities require Gro for their function in Drosophila embryos. Our results indicate that the carboxy-terminal region of Hairy and a repressor domain from the En homeodomain protein both need Gro to function in vivo. In contrast, repressor domains from the Snail (Sna), Eve, Kr, and Knirps (Kni) proteins can act independently of Gro. These results suggest that Gro mediates repression by a subset of negative regulators in Drosophila.

\section{Results}

Gro is required for Hairy repression of Sxl transcription

Gro appears to play several roles during early development and it can be difficult to distinguish between its direct and indirect effects in vivo. For example, segmentation in gro mutant embryos is altered dramatical ly be fore the action of Hairy (Paroush et al . 1994, 1997), therefore Hairy's requirement for Gro could be indirect. To partially circumvent these problems we have explored the role of Gro in repression using an assay in which ectopic Hairy interferes with expression of the SxI sex determination gene (Parkhurst et al. 1990). Sxl transcription is initiated selectively in early female embryos by a set of activator proteins encoded on the $X$ chromosome (Cline 1980, 1988; Bell et al. 1988; Keyes et al. 1992; for review, see Parkhurst and Meneely 1994). In male embryos, SxI remains off because these activators are outcompeted successfully by autosomal repressors, which include the Hairy-rel ated factor D pn (Younger-Shepherd et al. 1992; Barbash and Cline 1995). Although Hairy is not normally involved in sex determination, its misexpression at early blastoderm stages mimics Dpn's activity and inhibits Sxl transcription (Parkhurst et al. 1990). Thus, ectopic Hairy expression driven by the hunchback (hb) gap gene promoter, which is active in the anterior half of the blastoderm embryo at the time of Sxl initiation (nuclear cycles 11-13), leads to repression of SxI in the anterior of female embryos. This can be monitored by a monoclonal antibody specific for active, full-length SxI protein, which normally stains only female embryos (Fig. 1A). The hb-h assay offers inherent advantages for exploring the role of Gro in repression by Hairy. First, regulation of $\mathrm{Sxl}$ is among the first transcriptional switches in Drosophila, and therefore, is probably independent of other Gro roles in embryonic development. Also, zygotic activity of the hb promoter is largely normal in gro mutant embryos (Fig. 1C), therefore it drives equival ent transgene expression in gro and wild-type embryos.

To examine whether Hairy requi res Gro to repress SxI, we analyzed the effects of ectopic $h$ transcription in embryos deprived of maternal Gro activity. As gro homozygous females are lethal, such embryos were obtained from mosaic females in which all embryos laid derive from gro ${ }^{-}$germ cells (see $M$ aterial s and $M$ ethods). These experiments involved the gro ${ }^{\mathrm{E} 48}$ and gro $^{\mathrm{E} 75}$ alleles, which behave as nulls in genetic tests (Preiss et al . 1988; Delidakis et al. 1991) and Df(3R)BX22, a deficiency that removes gro-coding sequences and adjacent $\mathrm{E}(\mathrm{spl})$ genes that are not expressed maternally, and whose loss should not affect early transcriptional regulation (Preiss et al. 1988; Shepard et al. 1989). In general, all three gro alleles yiel ded equivalent results. If repression of Sxl by Hairy depends on Gro, anterior Sxl expression should be restored in hb-h embryos from gro mutant mothers (hb- $h$, gro embryos). Indeed, all such embryos express SxI both anteriorly and posteriorly (Fig. 1B). Thus, Hairy is unable to repress SxI transcription in gro embryos.

Replacement of the carboxyl terminus of Hairy by the Eve repressor domain generates a Gro-independent repressor

The above experiment argues that Gro is necessary for 

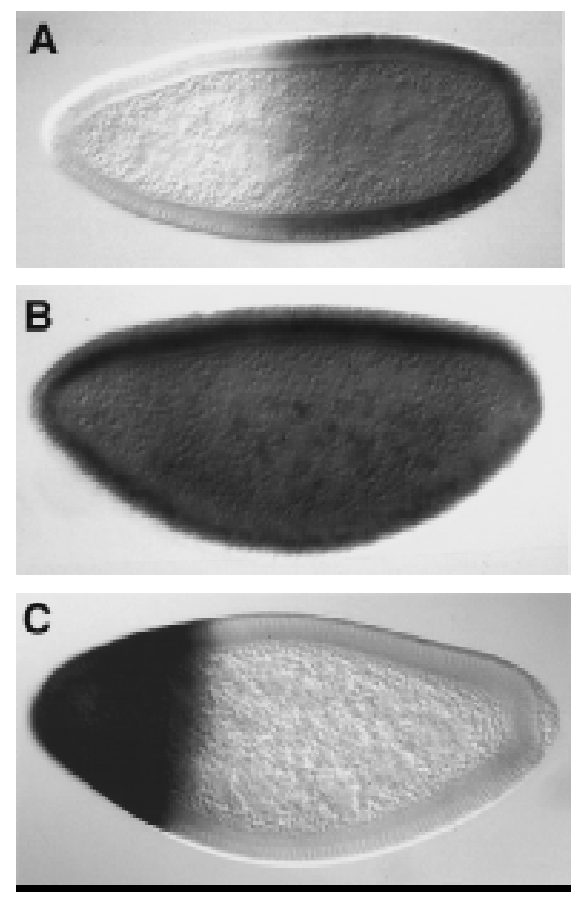

Figure 1. Hairy requires Gro for repression of SxI. Effect of the $\mathrm{hb}-\mathrm{h}$ construct in otherwise wild-type $(\mathrm{A})$ or $\operatorname{gro}^{\mathrm{E} 48}(\mathrm{~B})$ female blastoderm embryos. Efficient repression at the anterior is observed in the presence but not in the absence of Gro. Embryos were stained with an antibody against active SxI protein. (C) Pattern of lacZ mRN A expression directed by the hb promoter in gro embryos; efficient activity of the promoter is observed in the anterior region of the embryo. In this and subsequent figures anterior is to the left and dorsal is up.

Hairy to repress $S x I$, and is consistent with previous evidence that such repression depends on the WRPW Gro- binding domain (Dawson et al. 1995). This result also offers an assay to test the requirement of Gro for the activity of other repressor domains. We reasoned that replacement of the Hairy carboxy-terminal domain by heterologous repressor domains would generate Hairy repressor derivatives whose repression of SxI might be either dependent or independent of Gro. To test this idea, we made a Hairy ${ }^{\text {Eve }}$ fusion derivative by replacing the carboxy-terminal 69 amino acids of Hairy by a repression domain from the Eve segmentation protein ( $E v \mathrm{e}^{\mathrm{R}}$; amino acids 140-247; Fig. 2A) that mediates repression in cultured cells when fused to a heterologous DNA-binding domain (Han and Manley 1993a). Eve ${ }^{R}$ is believed to act by direct interactions with the basal transcription complex (A ustin and Biggin 1995; Um et al. 1995) and therefore is a good candi date for acting independently of Gro.

We first examined the effects of $h b-h^{\text {eve }}$ in otherwise wild-type embryos. $h b-h^{\text {eve }}$ does not cause the high levels of female lethality normally associated with hb-h. Viability of transformant females in several independent lines is typically $>80 \%$ (Fig. $2 A$; data not shown). However, three different hb-h ${ }^{\text {eve }}$ lines examined show effective repression of anterior SxI (Fig. 2B), similar to that caused by hb-h. In these lines, Sxl expression recovers partially as devel opment proceeds (mainly after stage 9; data not shown), suggesting that residual, undetectable SxI transcription in early $h b-h^{\text {eve }}$ embryos is sufficient to trigger Sxl maintenance and rescue most females to adulthood. Repression by Hairy ${ }^{E v e}$ is dependent on Eve ${ }^{R}$ because the equivalent truncated Hairy protein lacking the carboxy-terminal 69 amino acids (Hairy ${ }^{1-268}$ ) is inactive in the hb assay (Fig. 2A; data not shown).

To test whether Hairy ${ }^{\text {Eve }}$ is dependent on Gro activity, we monitored its effects on Sxl expression in gro mutant embryos. Anterior Sxl expression is repressed efficiently in $h b-h^{\text {eve }}$, gro embryos (Fig. 2B), showing that Eve ${ }^{R}$
Figure 2. Effects of Hairy repressor chimeras in otherwise wild-type or gro embryos. (A) Diagram of Hairy derivatives expressed under the control of the hb promoter and their effects on female viability and SxI expression. The degree of female lethality is represented by crosses: $(++H)$ most lines show $>80 \%$ lethality; $(+)$ most lines show $<30 \%$ lethality; ( $\rightarrow$ no lethality detected. (B) Effects on Sxl expression of hb-heve, hb-hen, hb-h ${ }^{\text {sna }}$, hb-h $h^{\mathrm{Kr}}$, and hb$h^{\mathrm{kni}}$ in otherwise wild-type or gro ${ }^{\mathrm{E} 48} \mathrm{em}$ bryos. Repression of Sxl is observed in all cases, except for hb-hen in gro embryos.
A

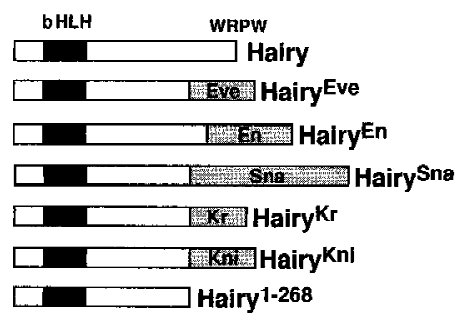

\begin{tabular}{ccc}
$\begin{array}{c}\text { Female } \\
\text { lethality }\end{array}$ & \multicolumn{2}{l}{ Sxl repression } \\
\cline { 3 - 3 }+++ & Wt & gro \\
+ & Yes & Yes \\
+++ & Yes & No \\
+++ & Yes & Yes \\
+ & Yes & Yes \\
+ & Yes & Yes \\
- & No & nd \\
& &
\end{tabular}

B

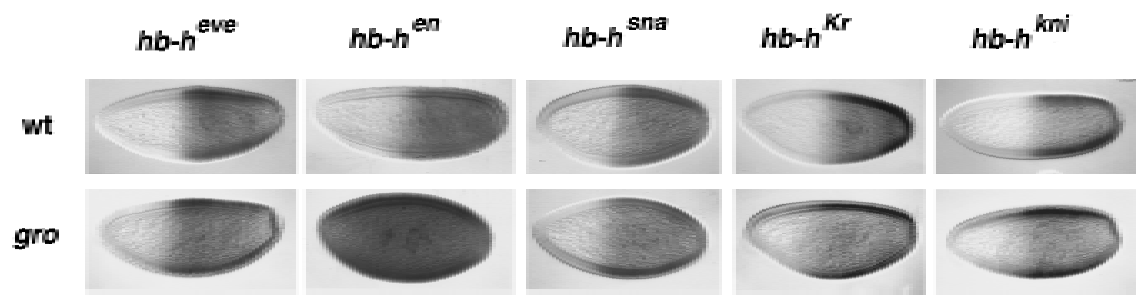


functions independently of Gro. This result al so provides direct evidence that the failure of Hairy to repress Sxl in gro embryos results from a loss of activity of the carboxyterminal WRPW domain, strongly suggesting that the latter acts through Gro in vivo.

\section{A repression domain from En is Gro dependent}

We then tested Hairy ${ }^{\text {En }}$ (Fig. 2A), a chimeric protein including Hairy ${ }^{1-286}$ fused to a repressor domain from the En segmentation protein (amino acids 168-298). This domain $\left(E n^{R}\right)$ has been shown previously to mediate potent repression in Drosophila cells and in other cell and embryonic systems Jaynes and O'Farrell 1991; Han and M anley 1993b; Badiani et al. 1994; John et al. 1995; ConIon et al. 1996; Smith and Jaynes 1996). Indeed, $\mathrm{hb}^{-\mathrm{h}^{\mathrm{en}}}$ behaves as a strong repressor of Sxl; in most $\mathrm{hb}-\mathrm{h}^{\text {en }}$ lines, viability of females drops to $<10 \%$ of that of males (Fig. $2 \mathrm{~A}$; data not shown), and efficient repression is observed in the anterior half of all transformant embryos (Fig. 2B). Strikingly, hb-hen is unable to repress Sxl in gro ${ }^{\mathrm{E} 48}$ (Fig. $2 \mathrm{~B}$ ), gro ${ }^{\mathrm{E} 75}$, or $\mathrm{BX} 22$ embryos (data not shown). These results indicate that $\mathrm{En}^{\mathrm{R}}$ is a second Gro-dependent domain.

We also examined three further repressor domains, from the Sna (amino acids 1-244), Kr (amino acids 26114), and Kni (amino acids 159-257) proteins that function as negative regul ators of transcription in blastoderm embryos (Gerwin et al. 1994; Licht et al. 1994; Arnosti et al. 1996; Gray and Levine 1996a; Fig. 2A). All three fusions have detrimental effects on female viability when expressed from the hb promoter in a wild-type background: Hairy ${ }^{\text {Sna }}$ leads to high levels of female lethality $(>80 \%) ; \mathrm{Hairy}{ }^{\mathrm{Kr}}$ and Hairy ${ }^{\mathrm{Kni}}$ have weaker effects, similar to that of Hairy Eve (Fig. 2A; data not shown). N evertheless, all three constructs repress Sxl efficiently in blastoderm embryos (Fig. 2B). All three fusions also repress SxI in gro mutant embryos (Fig. 2B), indicating that, at least in our assay, none of these repressor domains requires Gro.

Repression of $\mathrm{ftz}$ by Hairy ${ }^{\mathrm{En}}$ is also Gro dependent

The above experiments indicate that $\mathrm{En}^{\mathrm{R}}$ mediates repression of Sxl in a Gro-dependent manner. To test whether such a requirement is specific to Sxl regulation or shared by other promoters we examined the ability of Hairy ${ }^{E n}$ to repress $\mathrm{ftz}$. Previous results suggest that $\mathrm{ftz}$ is a direct target of repression by Hairy/Gro (Carroll and Scott 1986; Howard and Ingham 1986; Ish-Horowicz and Pinchin 1987; Paroush et al. 1994; Jiménez et al. 1996). We find that ectopic Hairy expression under the control of a heat-shock promoter (hs-h) leads to rapid and efficient repression of $\mathrm{ftz}$ transcription in wild-type, but not gro embryos (Fig. 3; M aterial s and M ethods). In contrast, Hairy derivatives lacking the carboxy-terminal WRPW motif are unable to repress ftz in this assay (Jiménez et al. 1996).

We generated transformant hs- $h^{\text {en }}$ lines and monitored ftz expression after heat-shock induction (M ateri- als and M ethods). In embryos carrying the hs- $h^{\text {en }}$ transgene, $\mathrm{ftz}$ expression is completely abolished within 30 min of the start of a 10-min heat shock (Fig. 3), as occurs when wild-type Hairy is expressed ectopically (IshHorowicz and Pinchin 1987). However, ftz transcription is unaffected by hs-h ${ }^{\text {en }}$ in gro mutant embryos (Fig. 3), indicating that $\mathrm{En}^{\mathrm{R}}$ requires $\mathrm{Gro}$ to repress both $\mathrm{ftz}$ and Sxl. Fai lure to repress $\mathrm{ftz}$ is not attributable to inefficient induction of Hairy En in gro embryos, because the chimeric protein can be detected readily using an antibody against Hairy (data not shown).

In contrast, expression of Hairy Eve under heat-shock control results in efficient repression of $\mathrm{ftz}$ both in wildtype and gro embryos (Fig. 3). These results are consistent with those obtained in the hb assay, and show that the Eve domain can repress different promoters independently of Gro (see Discussion).

\section{Repression of eve by En protein requires Gro}

The above results indicate that Gro mediates the activity of $\mathrm{En}^{\mathrm{R}}$. Therefore, we asked whether $\mathrm{Gro}$ is required for repression by native En. The En protein functions as a regulator of anteroposterior pattern formation both in the embryo and the adult (for review, see Cohen 1993; Martinez Arias 1993). Although the activity of En as a repressor has been mainly characterized in cultured cells, there is al so evidence that it inhibits transcription of various target genes in vivo (Sanicola et al. 1995; Schwartz et al. 1995). eve is one such target because ec-

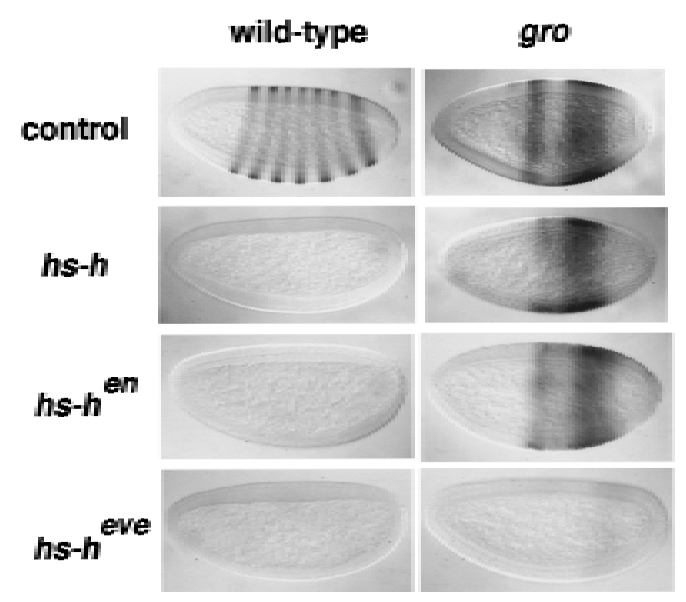

Figure 3. Effects of Hairy, Hairy En, and Hairy Eve on ftz transcription in the presence and absence of Gro. The Hairy derivatives were expressed in blastoderm embryos under the control of a heat-shock promoter (see $M$ aterials and $M$ ethods). The normal patterns of ftz mRNA in control wild-type and gro embryos are also shown. Because of the effects of gro on gap gene expression, ftz is not expressed in stripes in gro embryos, but occupies a broad domain in the trunk region. All three heat-shock constructs repress $\mathrm{ftz}$ in wild-type embryos, but only hs-heve leads to significant repression in gro embryos. The gro embryos were derived from gro ${ }^{\mathrm{B} \times 22}$ (control and hs-h) or gro ${ }^{\mathrm{E} 48}$ ( $\mathrm{hs}-\mathrm{h}^{\mathrm{en}}$ and hs- $h^{\text {eve) }}$ mosaic females. 
topic en expression in blastoderm embryos causes rapid repression of eve (John et al. 1995). Also, after the blastoderm stage eve expression persists for longer than normal in en mutant embryos (Harding et al. 1986). Thus, En is likely to act as a negative regulator of late eve transcription.

As shown in Figure 4C, ectopic en expression under the control of a heat-shock promoter clearly represses eve in embryos derived from wild-type females (see Materials and M ethods). Repression is particularly efficient for eve stripes 2, 5, and 7 and even the more resistant stripe 4 is fully repressed in $\sim 60 \%$ of embryos (101 of 166). In gro embryos, eve transcripts accumulate in one or two broad central domains, not in stripes (Fig. 4B). This expression is not repressed after hs-en induction (Fig. 4D), although efficient accumulation of ectopic En protein is readily detected in those embryos (data not shown). Therefore, Gro is required for En to repress eve transcription.

\section{Hairy ${ }^{\text {En }}$ binds to Gro in vitro}

One mechanism whereby En might direct Gro-dependent repression is if the $\mathrm{En}^{\mathrm{R}}$ repression domain binds $\mathrm{Gro}$ di rectly and recruits it to target promoters. Therefore, we compared the ability of full-length Hairy and Hairy ${ }^{\mathrm{En}}$ to bind to Gro in vitro. The Hairy derivatives were expressed in bacteria as gl utathione S-transferase (GST) fusions, immobilized on glutathione-Sepharose beads, and tested for their ability to retain radiolabeled Gro protein. Both GST-Hairy and GST-Hairy ${ }^{\mathrm{En}}$ bind Gro, whereas control GST fusions (two different Hairy carboxy-terminal truncations lacking the WRPW tetrapeptide and the Hairy ${ }^{E v e}$ and Hairy ${ }^{\text {Sna }}$ chimeras), show little or no binding (Fig. 5A). These results suggest that the $\mathrm{En}^{\mathrm{R}}$ domain inhibits transcription by direct interactions with Gro.

$\mathrm{En}^{\mathrm{R}}$ does not contain a recognizable WRPW-like sequence, suggesting that its binding to $G$ ro is mediated by other protein motifs. To begin the identification of such

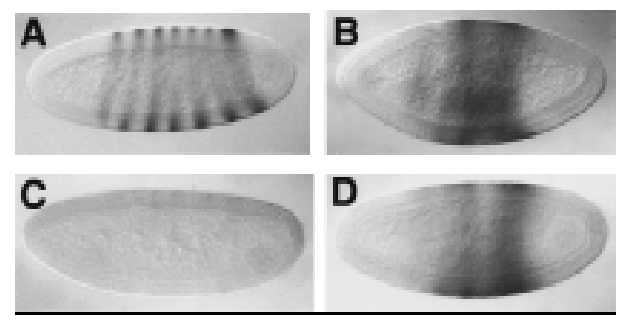

Figure 4. Ectopic En represses eve expression in wild-type but not in gro embryos. Wild-type pattern of eve mRNA (A) and its repression in a heat-shocked hs-en embryo (C). Pattern of eve in a control gro ${ }^{\mathrm{E} 48}$ mutant embryo (B) and in a heat-shocked gro ${ }^{\mathrm{E} 48}$ embryo carrying the hs-en construct (D); no significant repression is observed. As in the case of $\mathrm{ftz}$, eve transcripts are not expressed in stripes in gro embryos, but accumulate in one or two broad central domains.

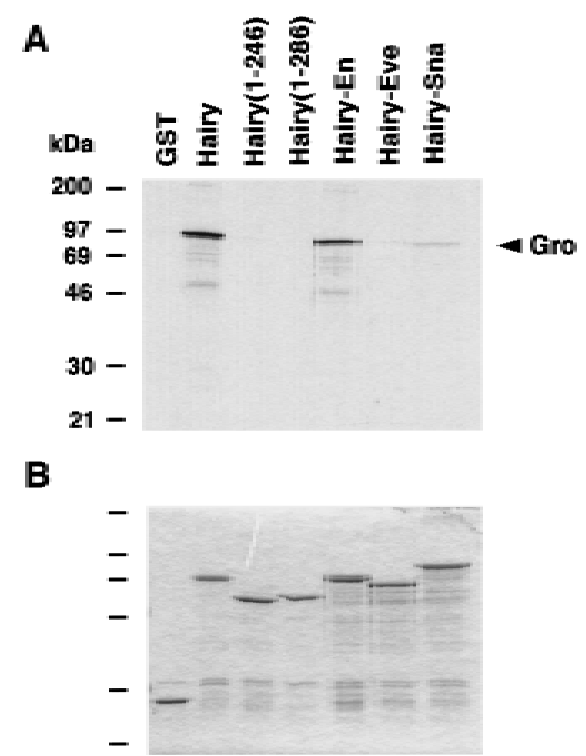

Figure 5. Gro binds in vitro to Hairy En (A) Radiolabeled Gro protein was incubated with various GST-Hairy derivatives bound to glutathione-Sepharose beads. After washing the beads, the retained Gro protein was visualized by SDS-PAGE and autoradiography. (B) Coomassie staining showing the integrity of the different GST fusions after incubation with Gro.

motifs, we tested several Hairy ${ }^{\mathrm{En}}$ derivatives with deletions in the $E n^{R}$ domain for their ability to bind to Gro in vitro. The original $\mathrm{En}^{\mathrm{R}}$ domain used in our experiments contains two subdomains (regions $C$ and D, see Fig. 6) that were initially characterized by $\mathrm{Han}$ and Manley (1993b) in cultured cells. These researchers found a stronger repressor activity for region $D$ than for region $C$. However, recent experiments using an assay in blastoderm embryos indi cate that regi on $C$ is more active than region D in vivo (Smith and Jaynes 1996). We find that Hairy ${ }^{\text {En }}$ proteins lacking region D are able to bind to Gro with the same affinity as the intact Hairy ${ }^{\mathrm{En}}$ chimera (Fig. 6). In contrast, deletion of region $C$ results in a fourfold decrease in binding activity. These results indicate that although region $D$ can contribute to the interaction, most of the binding activity resides within regi on $\mathrm{C}$. Because the study of Smith and Jaynes (1996) suggested that most of the function of the $C$ domain resides in a conserved element (called eh1), present in other homeodomain proteins such as Goosecoid, we examined the effects of removing this element in our binding assay. As shown in Figure 6, two different del etions of the eh1 motif result in a decrease in Gro binding comparable to that caused by removal of the whole $C$ region. These results point to a important role of the ehl region in the ability of $\mathrm{En}^{\mathrm{R}}$ to bind to Gro. M oreover, the degree of Gro binding for the different constructs correl ates well with their in vivo repressor activity as determined by Smith and Jaynes (1996), suggesting that the eh1/Gro interaction is indeed functionally significant.

The ability of Gro to bind to the Hairy and En repressor domains raises the question of whether these asso- 


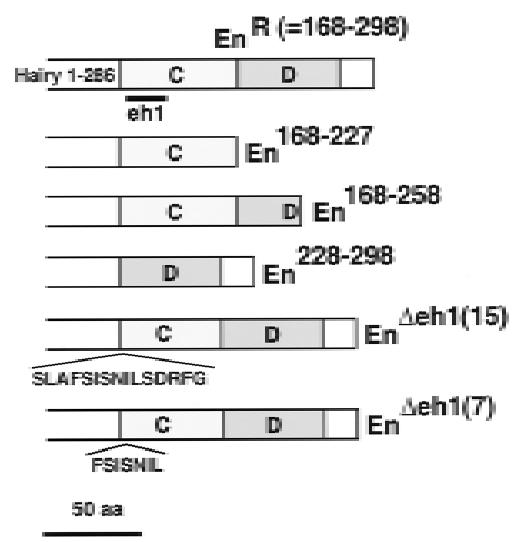

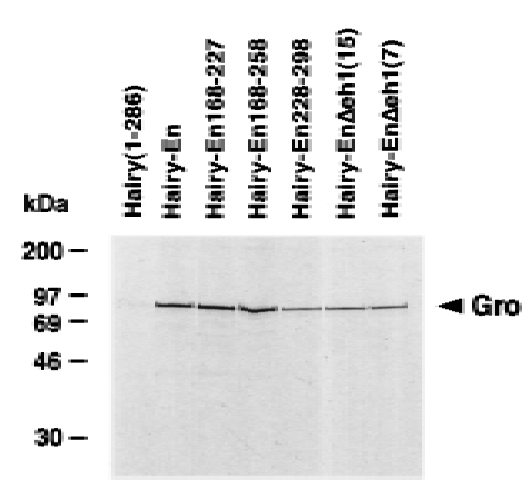

Figure 6. Mapping of sequences within $\mathrm{En}^{\mathrm{R}}$ responsible for binding to Gro. A diagram of different $\mathrm{En}^{\mathrm{R}}$ del etion mutants is shown. These mutations were introduced in the original GSTHairy ${ }^{E n}$ construct and examined for their ability to bind full-length Gro. Deletions of region D (constructs $\mathrm{En}^{168-227}$ and $\mathrm{En}^{168-258}$ ) do not affect the interaction with Gro. In contrast, del etion of region $C$ (construct $\mathrm{En}^{228-298}$ ) causes a fourfold decrease in the binding. A similar result is obtained after eliminating 15 or 7 amino acids $\left[E n^{\Delta e h 1(15)}\right.$ or $E n^{\Delta e h 1(7)}$, respectively] that constitute the conserved eh1 motif (Smith and Jaynes 1996). ciations are mediated by a single or different regions of Gro. Therefore, we compared the binding in vitro of various Gro deletion derivatives to Hairy and Hairy ${ }^{\mathrm{n}}$. We first examined two Gro mutants lacking either the carboxy-terminal half of the protein (including the WD repeats) or the complementary amino-terminal domain (Gro ${ }^{\mathrm{WD}}$ and GroWD, respectively; see Fig. 7). Both mutants show a dramatic loss of binding activity to Hairy and Hairy En, although we still detect weak binding of

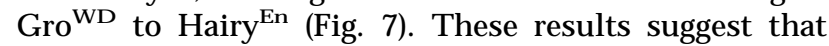
both halves of Gro are required for full interaction with both repressor domains. These findings differ from our previous result that a central domain of Gro, lacking al I WD sequences, is sufficient for the interaction with Hairy in yeast (Paroush et al. 1994). Although we cannot explain this difference, the stronger and more specific binding of Gro to Hairy in vitro than in yeast (Paroush et al. 1994) favors a role for the WD repeats in this interaction (see below).

To test further the requirement of the WD region for binding to Hairy and Hairy ${ }^{E n}$, we generated three additional Gro derivatives with progressive del etions of carboxy-terminal WD repeats (Fig. 7). All three derivatives show very weak interactions with full-length Hairy, similar to that of the Hairy ${ }^{1-286}$ negative control, again suggesting that the integrity of the WD region is essential for binding to Hairy. In contrast, Gro ${ }^{\triangle W D 6}$ and Gro ${ }^{\Delta W D 5,6}$ (lacking the sixth, and the fifth and sixth WD repeats, respectively) retain significant binding to Hairy ${ }^{\mathrm{E}}$. These results suggest that these two repeats contribute toward, but are not essential for binding to $\mathrm{En}^{\mathrm{R}}$, and are consistent with the existence of different structural requirements for binding of Gro to Hairy and En repressor domains.

\section{Discussion}

A few studies suggest that active repression often involves corepressors. These proteins are believed to act as molecular bridges between repressor domains and target
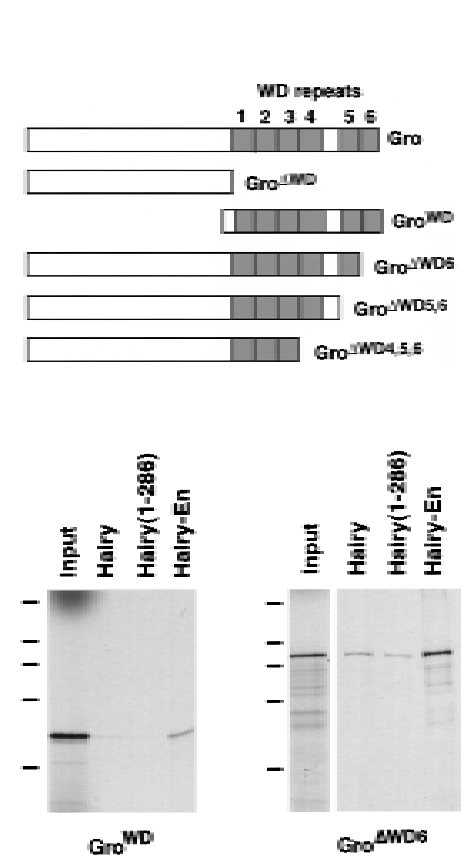
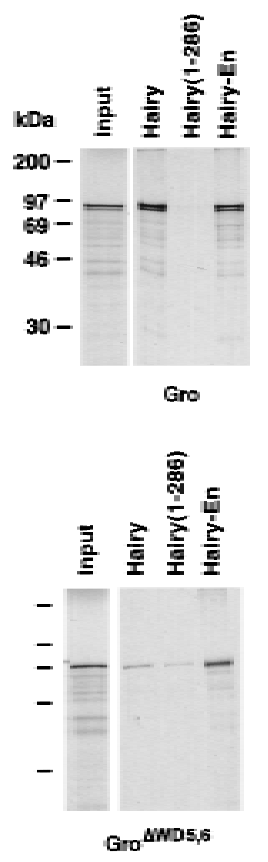
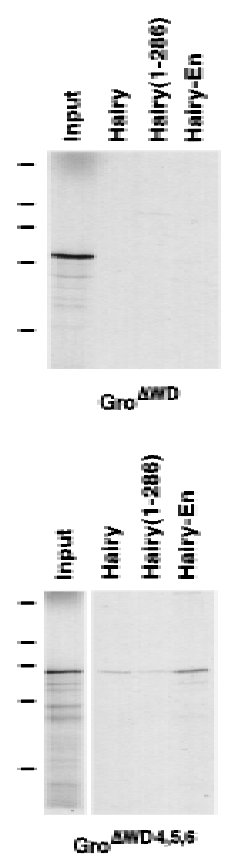

Figure 7. Binding of Hairy and Hairy ${ }^{\mathrm{En}}$ to Gro deletion mutants. A diagram of the different Gro derivatives analyzed is shown. These derivatives were assayed for binding to Hairy, Hairy ${ }^{1-286}$ (a truncation similar to Hairy ${ }^{E n}$ but lacking $E^{R}$ ), and Hairy ${ }^{E n}$. Equivalent aliquots of labeled Gro derivatives are shown as a control for the strength of the interactions (Input lanes). Gro ${ }^{\Delta W D}$ and GrowD show weak or no binding to either Hairy or Hairy ${ }^{\mathrm{En}}$. Gro derivatives with progressive WD repeat deletions also show very weak binding to Hairy, but $\mathrm{Gro}^{\Delta 6}$ and $\mathrm{Gro}^{\Delta 5,6}$ interact significantly with Hairy ${ }^{\mathrm{E}}$. 
proteins such as components of the basal transcription complex. A prevailing question is whether corepressors act in concert with many or only a few repressors. In this paper, we provide the first systematic attempt to assess the specificity of a corepressor in higher eukaryotes. We find that Gro is not only required for repression by Hairy, but that it also mediates specifically the activity of a domain from En. In contrast, repressor domains from the $\mathrm{Sna}$, Eve, $\mathrm{Kr}$, and $\mathrm{Kni}$ proteins are active in the absence of Gro. These results argue that Gro is required for the activity of a subset of repressors in Drosophila.

Our results show that ectopic Hairy fails to repress either Sxl or ftz transcription in gro mutant embryos. In contrast, Hairy chimeric proteins in which the Gro-binding WRPW motif is substituted by alternative repressor domains can act independently of Gro. Thus, Hairy is able to direct repression through the Eve, Sna, Kr, or Kni repressor domains in gro mutant embryos, but not through its own WRPW motif. These results render unlikely the explanation that Hairy requires Gro directly or indirectly to bind to target promoters (see al so Jiménez et al. 1996). Together with the in vitro results showing direct interactions between the WRPW motif and Gro, our results indicate that Gro functions as an authentic corepressor for Hairy (Paroush et al. 1994).

Recently, Aronson et al . (1997) have provided evi dence that Runt, a transcriptional regulator unrelated to Hairy but that contains at its carboxyl terminus a WRPY sequence reminiscent of the WRPW motif, also interacts with Gro through this sequence. Thus, Gro also mediates some of Runt's repressor activities during segmentation.

The Eve, Sna, Kr, and Kni domains must have a mechanism of action that is independent of Gro. In contrast, En ${ }^{\mathrm{R}}$ appears functionally linked to Gro, as Hairy ${ }^{\mathrm{En}}$ represses transcription efficiently in wild-type but not gro mutant embryos. Indeed, native En requires Gro to repress eve in vivo and we have shown that $\mathrm{En}^{\mathrm{R}}$ is able to bind Gro in vitro. These results suggest that, like the WRPW motif, En ${ }^{\mathrm{R}}$ functions by recruiting Gro to target promoters. This association depends on the eh1 motif, which is conserved within En homologous genes, essential for repression in vivo, and al so present in other homeodomain proteins from various organisms (see Smith and Jaynes 1996). Thus, these proteins may be transcriptional repressors that interact with Gro or its homologs in other animals.

Our results indicate that Gro acts as a multifunctional protein that integrates signals from different transcriptional repressors. These repressors can be unrelated structurally, as there are no significant similarities between Hairy and En, either within or outside their repressor domains. This illustrates that repressor domains classified apart according to their structure may have a common mechanism of action. Similarly, TUP1 appears to mediate repression by different classes of repressors such as $\alpha 2$ and MIG1 (Keleher et al. 1992; Treitel and Carlson 1995). Conversely, repressor domains with shared features may have different targets; En and Eve are both homeodomain proteins with alanine-rich repressor domains, yet only the former acts through Gro.

The eh1 and WRPW motifs appear unrelated, suggesting that the associations of these repressor domains with Gro involve different mol ecular interfaces. We addressed this issue by examining which regi ons in Gro mediate its binding to Hairy and Hairy ${ }^{\mathrm{En}}$. Our results show that sequences both within and outsi de the WD repeats are important for each of these interactions. However, Hairy and $\mathrm{En}^{\mathrm{R}}$ appear to show different requirements for the WD repeats. The most carboxy-terminal fifth and sixth WD repeats are necessary for binding to Hairy, but are partially dispensable for the interaction with $\mathrm{En}^{\mathrm{R}}$. Thus, Hairy must either bind the sixth repeat or require the integrity of the whole WD region. Crystal structure analyses of other WD proteins have shown that this region adopts a complex conformation called a $\beta$-propeller (Sondek et al. 1996; Wall et al. 1996), and perhaps Hairy recognizes features characteristic of such a structure. In contrast, $\mathrm{En}^{\mathrm{R}}$ may target Gro motifs that do not necessarily need to be assembled into a full $\beta$-propeller.

Gro is probably only essential for some En functions. Thus, reduced or absent gro activity in the posterior compartment of imaginal discs does not seem to recapitulate the phenotype of en loss-of-function mutations (de Celis and Ruiz-Gómez 1995; Heitzler et al. 1996), suggesting that Gro may be dispensable for repression by En in some adult tissues. Similarly, Runt appears to repress at least one target gene independently of Gro (Aronson et al. 1997).

How might Gro mediate repression? We favor a model in which Gro is recruited to target promoters by specific DNA-binding proteins and then represses transcription (Paroush et al. 1994). This view is supported by recent experiments showing that Gro can mediate significant levels of repression in cultured cells when targeted to a promoter through a heterologous DN A-binding domain (Fisher et al. 1996). An alternative model is that Gro is a component of the basal transcriptional machinery and functions as a target for repressors such as Hairy or En. This model appears plausible in light of the finding that dTAF80, a Drosophila WD repeat protein that may be required for repression, is a component of the general TFIID complex (Dynlacht et al. 1993; Kokubo et al. 1993). However, studies on polytene chromosomes show that Gro local izes to a subset of chromosome bands, suggesting that it is not present at all promoters (Bettler et al. 1996). Although these results do not exclude the possibility that Gro is a component of the transcription complex assembled only in a subset of promoters, they favor the recruitment model of Gro action.

Once recruited to target promoters, Gro could interfere with transcription in several ways. The simplest possibility is that Gro interacts directly with components of the basal transcriptional machinery to disrupt their assembly, structure, or accessibility. A particular aspect of this model is that Gro might interfere with components of the transcriptional machinery specifically required for transcriptional activation [e.g., the TATA-binding protein (TBP)-associated factors (TAFs); 
for review, see Verrijzer and Tjian 1996]. It has been shown that in cultured cells $\mathrm{En}^{\mathrm{R}}$ appears to mediate strong repression of promoters stimulated by activator proteins, while being unable to inhibit transcription of basal promoters (Han and Manley 1993b). Thus, these effects may reflect the mechanism of Gro action, and may also be a feature of repression by Hairy. Alternatively, Gro could inhibit transcription by "quenching" (i.e., by interacting with a promoter-bound activator and interfering with its ability to contact the basal machinery). Finally, it is possible that Gro acts by influencing chromatin organization directly. Another WD-containing protein, Extra-sex-combs, is thought to act as a repressor by altering chromatin structure (Gutjahr et al. 1995; Sathe and Harte 1995; Simon et al. 1995), and repression by TUP1 appears to rely on interactions with histones H3 and H4 (Edmondson et al. 1996). Moreover, a series of recent experiments suggest that the corepressor complex mRPD/mSin3/N-CoR modulates chromatin conformation through histone deacetylation (for review, see Pazin and Kadonaga 1997; Wolffe 1997). Future biochemical approaches will address whether Gro uses these or other activities to modify chromatin behavior.

Previous work has led to a distinction between repressors that need to lie close ( $<150 \mathrm{bp}$ ) to activators or the basal complex to function (short-range repressors) and those that can act over longer distances (long-range repressors; Gray and Levine 1996b). It has been suggested that this difference may result in distinct modes of regulation of a complex promoter. Short-range repressors could act locally to inhibit a particular enhancer, while leaving other enhancers free to activate expression; in contrast, long-range repressors would act dominantly to ensure that the promoter is repressed completely (Gray et al. 1994; Arnosti et al. 1996; Gray and Levine 1996a; Barolo and Levine 1997). We find that three repressor domains that come from short-range repressors (Sna, Kr, and Kni) all act independently of Gro. In contrast, recent experiments show that Hairy behaves as a long-range repressor on synthetic promoters (Barolo and Levine 1997), an effect that should depend on Gro. These results suggest that Gro may be a long-range, dominant corepressor. However, the Hairy ${ }^{\mathrm{Sna}}$, Hairy ${ }^{\mathrm{Kr}}$, and Hairy ${ }^{\mathrm{Kni}}$ chimeras (in which Hairy has presumably been converted from a long- to short-range repressor) are still able to repress the endogenous SxI promoter. These results indicate that short- and long-range repressors are to some extent interchangeable and do not necessarily exert different modes of promoter regulation.

In conclusion, our results indicate that Gro is not generally required for repression, but acts as a dedicated corepressor for a subset of negative regulators, including Hairy and En. The evolutionary conservation of Gro, Hairy, and En suggests that similar repressor/corepressor associations will al so operate in vertebrates. Indeed, $\mathrm{En}^{\mathrm{R}}$ is much used as a portable repressor domain in a variety of heterologous vertebrate systems (for example, see Badiani et al. 1994; Conlon et al. 1996), and it will be interesting to determine whether its activity in vertebrates is al so Gro dependent. In yeast, the TUP1 protein is nec- essary for repression of a large number of genes, suggesting that it also acts in concert with different classes of negative regulators. These observations raise the possibility that at least a fraction of the repressors present in eukaryotes act through a relatively small number of corepressors. The characterization of repressor/corepressor interactions should be particularly fruitful in the search for common themes in transcriptional repression.

\section{Materials and methods}

Plasmids

Plasmid manipulations were performed according to standard protocols (Ausubel et al. 1987-97; Sambrook et al. 1989). The sequences encoding the different Hairy derivatives (except Hairy ${ }^{\mathrm{En}}$ ) were first prepared in pBluescript (Stratagene) by inserting PCR fragments encoding the repressor domains as BamHI-Xbal fragments downstream of the unique BamHI site in the $\mathrm{h}$ cDNA. The $\mathrm{h}^{\text {en }}$ fusion was made by first cloning a HindlI-BamHI fragment from the en CDNA upstream of a synthetic BamHI-Xbal linker containing an in-frame stop codon. This was followed by the insertion of a HindlII-Pvull h CDN A fragment upstream of the en HindlI site. All chimeric sequences were recovered as BstEII-Xbal fragments for cloning into pCaSpeR4. The hb-h plasmid is described in Parkhurst et al. (1990); all other hb-h derivatives were derived from it but constructed in the pCaSpeR4 "mini"'-white vector (Pirrotta 1988). These plasmids include a 750-bp Nhel-Xbal fragment from the hb gene (which includes the proximal promoter and all but 10 bp from the 5'-untranslated region), a 230-bp Xbal-BstEll fragment from the $h 5^{\prime}$ leader, Hairy fusion sequences (as BstEIIXbal fragments), and finally a 1.6-kb Xbal-EcoRV fragment from the $\mathrm{h} 3^{\prime}$-untranslated sequence. The Xbal sites in the hb and $h 5^{\prime}$ leaders were lost during cloning (see Parkhurst et al. 1990). The unique Xbal site between the $h$ coding and the $3^{\prime}$-end sequences was created during the cloning procedure. Final constructs were generated by assembling $h b-h$ sequences between the Nhel and Hpal sites of pCaSpeR4.

The hs-heve construct was made by cloning the ${ }^{\text {eve }}$ sequences as a Hindll-Xbal fragment in pCaSpeR-hs (Pirrotta 1988) digested with $\mathrm{Hpal}$ and Xbal. hs- $h^{\text {en }}$ was constructed by replacing a $\mathrm{Notl}-\mathrm{Xbal}$ fragment in hs-h $\mathrm{h}^{1-268-V P 16}$ (containing Hairy amino acids 246-268 and the VP16 activation domain; Jiménez et al. 1996) by the equival ent $\mathrm{N}$ otl-Xbal $\mathrm{h}^{\text {en }}$ fragment.

Plasmids encoding GST-Hairy and GST-Hairy ${ }^{1-246}$ (=Hairy $\Delta \mathrm{N}$ otl) were described in Paroush et al. (1994). Plasmids for all other GST chimeras were made by cloning in-frame the relevant Hairy-derived sequences into PZEX, a modification of pGEX-2T (Smith and Johnston 1988) containing the following polylinker cloning sites: EcoRI, Smal, BamHI, and Xhol.

pET-Gro plasmids were made by cloning full-length or partial gro sequences into $\mathrm{pET}-17 \mathrm{~b}$ and $\mathrm{pET}-3 \mathrm{a}$.

Additional details on the construction of the plasmids are available on request.

\section{Germ-line transformation}

P-element-mediated transformation was performed as described previously (Steller and Pirrotta 1985; Spradling 1986), selecting for G418-resistance (hb-h) or rescue of w eyes (all other constructs). In general, two or more independent lines were analyzed for each construct.

In the case of hb constructs, insertions on the $X$ chromosome were maintained in males using an attached $X$ chromosome [C(1)M3]; insertions on the autosomes were kept as unbal anced 
stocks selecting each generation for transformant males and nontransformant females. To analyze the effects of hb-h and $h b-h^{\text {en }}$ on gro embryos, we crossed mosaic gro females to males carrying the hb construct on the $\mathrm{X}$ chromosome, therefore all gro female embryos inherit the transgene.

For the experiments with hs- $h^{\text {en }}$ and hs-heve, we recombined two independent insertions of each construct into the same chromosome. Males carrying these recombinant chromosomes were then crossed to wild-type or mosaic gro females. To test the effects of hs-h, we used males carrying an insertion on the $X$ chromosome, HSH33, and homozygous for another insertion on the second, HSH21 (Ish-Horowicz and Pinchin 1987).

The hs-en flies were a kind gift of $A$. Jacinto and P. Ingham (University of Sheffield, UK).

\section{Germ-line clones and embryo analysis}

Embryos deprived of maternal gro function were obtained using the ovo ${ }^{D}$-FLP-FRT system (Chou et al. 1993). Briefly, males of the genotype hs-FLP1/Y; FRT[82B] ovo ${ }^{\mathrm{D} 1 / \mathrm{Sb}}$ were mated to FRT[82B] gro/TM3 females, and 2- to 4-day-old progeny heatshocked daily for $4 \mathrm{hr}$ at $37^{\circ} \mathrm{C}$ for the following 3-4 days. Ecl osed $\mathrm{TM}^{+} \mathrm{Sb}^{+}$virgin femal es were crossed to mal es carrying the hb and hs constructs. The progeny of these crosses was examined to confirm the expected lethality of gro mutant embryos.

In the experiments examining repression of Sxl, embryos were dechorionated 130-190 $\mathrm{min}$ after egg laying (AEL), and fixed for 12-15 min in heptane/4\% formal dehyde/PBS. The embryos were stained with a monoclonal antibody specific for the active form of Sxl (Bopp et al. 1991).

For the heat-shock experiments, embryos between 140 and $170 \mathrm{~min}$ AEL were heat shocked for $10-12 \mathrm{~min}$ at $36.5^{\circ} \mathrm{C}$ on wet tissue inside a prewarmed container in a water bath, a protocol that does not cause significant effects on wild-type embryos (Ish-Horowicz and Pinchin 1987). After heat shock, the embryos were al lowed to devel op for 20-25 min, dechorionated, and fixed as above for 15-20 min. In the case of stainings with antibodies against Hairy (gift of S.M. Pinchin, this laboratory) and En (Patel et al. 1989), embryos were fixed for 12-15 $\mathrm{min}, 15 \mathrm{~min}$ after the heat shock. Whole-mount in situ hybridizations were performed using digoxygenin- and fluorescein-labeled RN A probes (Boehringer) as described (T autz and Pfeifle 1989; Klingler and Gergen 1993). In all cases, signals were detected using secondary anti bodies coupled to al kal ine phosphatase (Jackson Immunoresearch Laboratories, Boehringer), and embryos were mounted in methacrylate (JB-4, Polyscience) and examined under N omarski optics.

\section{In vitro protein-protein interactions}

GST fusions were expressed and purified essentially as described previously (Paroush et al. 1994) in the protease-deficient Escherichia coli strain SRP84 (gift of C. Higgins, ICRF). Binding assays were performed with equal amounts of fusion proteins (30 $\mu$ l of beads supplemented when necessary with beads from a blank bacterial extract) and $20-30 \mu \mathrm{l}$ of ${ }^{35}$ S-labeled Gro protein synthesized using the TNT-coupled rabbit reticulocyte lysate system (Promega), in $180 \mu \mathrm{l}$ of binding buffer [20 mM HEPES$\mathrm{KOH}$ (pH 7.9), $50 \mathrm{~mm} \mathrm{KCl}, 2.5 \mathrm{~mm} \mathrm{M} \mathrm{gCl}_{2}, 10 \%$ glycerol, $1 \mathrm{~mm}$ DTT, $0.2 \%$ N P-40] supplemented with $3 \mu$ of rabbit serum and $3 \mu \mathrm{l}$ of a $100 \mathrm{~mm}$ PMSF stock. Binding reactions were rolled overnight at $4^{\circ} \mathrm{C}$, and washed four times with $1 \mathrm{ml}$ of RIPA buffer [10 mM Tris- $\mathrm{HCl}$ (pH7.5), $150 \mathrm{~mm} \mathrm{NaCl}, 1 \mathrm{~mm}$ EDTA, and $0.2 \%$ NP-40]. The beads were boiled for $1 \mathrm{~min}$ in sample buffer and aliquots examined by electrophoresis, followed by Coomassie staining to confirm the integrity of the GST fusions, and autoradiography to detect bound Gro protein. The extent of Gro binding to mutant $\mathrm{En}^{\mathrm{R}}$ domains was quantified by a Phosphorlmager (Molecular Dynamics).

\section{Acknowledgments}

We thank members of the Developmental Genetics Laboratory (especially M. Wainwright and S. Pinchin) for their help and encouragement. We are also grateful to $P$. Verrijzer for hel pful comments on the manuscript, and to A. Jacinto, P. Ingham, D. Hartley, and M. Levine for fly stocks and plasmids. G.J. was supported by the European Community Human Capital and Mobility Program, the Imperial Cancer Research Fund, and the European M olecular Biology Organization. Z.P. was supported by the European Science Foundation, a Research Career Development Award of the Israel Cancer Research Fund, and by a research grant from the Israel Academy of Sciences and Humanities. This work was supported by the Imperial Cancer Research Fund. D.I.-H. is a Howard Hughes International Research Scholar.

The publication costs of this article were defrayed in part by payment of page charges. This article must therefore be hereby marked "advertisement" in accordance with 18 USC section 1734 solely to indicate this fact.

\section{References}

Alland, L., R. Muhle, H. Hou, J. Potes, L. Chin, N. Schreiberagus, and R.A. Depinho. 1997. Role for N-CoR and histone deacetylase in Sin3-mediated transcriptional repression. Nature 387: 49-55.

Arnosti, D.N., S. Gray, S. Barolo, J. Zhou, and M. Levine. 1996. The gap protein Knirps mediates both quenching and direct repression in the Drosophila embryo. EMBO J. 15: $3659-3666$.

Aronson, B.D., A.L. Fisher, K. Blechman, M. Caudy, and J. P. Gergen. 1997. Groucho-dependent and -independent repression activities of Runt domain proteins. Mol. Cell Biol. 17: 5581-5587.

Austin, R.J. and M.D. Biggin. 1995. A domain of the Evenskipped protein represses transcription by preventing TFIID binding to a promoter: Repression by cooperative blocking. Mol. Cell. Biol. 15: 4683-4693.

Ausubel, F.J., R. Brent, R.E. Kingston, D.D. Moore, J.G. Seidman, J.A. Smith, and K. Struhl, eds. 1987-97. In Current protocols in molecular biology. Greene Publishing Associates and Wiley-Interscience, N ew York, NY.

Badiani, P., P. Corbella, D. Kioussis, J. Marvel, and K. Weston. 1994. Dominant interfering allel es define a role for C-M yb in T-cell development. Genes \& Dev. 8: 770-782.

Barbash, D.A. and T.W. Cline. 1995. Genetic and molecular analysis of the autosomal component of the primary sex determination signal of Drosophila melanogaster. Genetics 141: 1451-1471.

Barolo, S. and M. Levine. 1997. Hairy mediates dominant repression in the Drosophila embryo. EMBO J. 16: 2883-2891.

Bell, L.R., E.M. Maine, P. Schedl, and T.W. Cline. 1988. Sexlethal, a Drosophila sex determination switch gene, exhibits sex-specific splicing and sequence similarity to RN A binding proteins. Cell 55: 1037-1046.

Bettler, D., S. Pearson, and B. Yedvobnick. 1996. The nuclear protein encoded by the Drosophila neurogenic gene mastermind is widely expressed and associates with specific chromosomal regions. Genetics 143: 859-875.

Bier, E., H. Vässin, S. Y ounger-Shepherd, L.Y. Jan, and Y.N . Jan. 1992. deadpan, an essential pan-neural gene in Drosophila, encodes a helix-loop-helix protein similar to the hairy gene 
product. Genes \& Dev. 6: 2137-2151.

Bopp, D., L.R. Bell, T.W. Cline, and P. Schedl. 1991. Developmental distribution of female-specific Sex-lethal proteins in Drosophila melanogaster. Genes \& Dev. 5: 403-415.

Carroll, S.B. and M.P. Scott. 1986. Zygotically active genes that affect the spatial expression of the fushi tarazu segmentation gene during early Drosophila embryogenesis. Cell 45: 113126.

Chou, T.B., E. Noll, and N. Perrimon. 1993. Autosomal P[ovoD1] dominant female-sterile insertions in Drosophila and their use in generating germ-line chimeras. Development 119: 1359-1369.

Cline, T.W. 1980. Maternal and zygotic sex-specific gene interactions in Drosophila melanogaster. Genetics 96: 903-926.

- - - 1988. Evidence that sisterless-a and sisterless-b are two of several discrete "numerator elements" of the X/A sex determination signal in Drosophila that switch SxI between two alternative stable expression states. Genetics 119: 829862.

Cohen, S.M. 1993. Imaginal disc development. In The development of Drosophila melanogaster (ed. M. Bate and A. M artinez Arias), pp. 747-842. Cold Spring Harbor Laboratory Press, Cold Spring Harbor, NY.

Conlon, F.L., S.G. Sedgwick, K.M. Weston, and J.C. Smith. 1996. Inhibition of Xbra transcription activation causes defects in mesodermal patterning and reveals autoregulation of Xbra in dorsal mesoderm. Development 122: 2427-2435.

Cowell, I.G. 1994. Repression versus activation in the control of gene-transcription. Trends Biochem. Sci. 19: 38-42.

Dawson, S.R., D.L. Turner, H. Weintraub, and S.M. Parkhurst. 1995. Specificity for the Hairy/Enhancer of split basic helixloop-helix (bHLH) proteins maps outside the bHLH domain and suggests two separable modes of transcriptional repression. Mol. Cell. Biol. 15: 6923-6931.

De Celis, J.F. and M. Ruiz-Gómez. 1995. groucho and hedgehog regulate engrailed expression in the anterior compartment of the Drosophila wing. Development 121: 3467-3476.

Delidakis, C. and S. Artavanis-T sakonas. 1992. The Enhancerof-split $[E(s p l)]$ locus of Drosophila encodes seven independent helix-loop-helix proteins. Proc. Natl. Acad. Sci. 89: 8731-8735.

Delidakis, C., A. Preiss, D.A. Hartley, and S. Artavanis-Tsakonas. 1991. Two genetically and molecularly distinct functions involved in early neurogenesis reside within the Enhancer-of-split locus of Drosophila melanogaster. Genetics 129: 803-823.

Dynlacht, B.D., R.O. Weinzierl, A. Admon, and R. Tjian. 1993. The dT AFII 80 subunit of Drosophila TFIID contains $\beta$-transducin repeats. Nature 363: 176-179.

Edmondson, D.G., M. Smith, and S.Y. Roth. 1996. Repression domain of the yeast global repressor TUP1 interacts directly with histones H3 and H4. Genes \& Dev. 10: 1247-1259.

Fisher, A.L., S. Ohsako, and M. Caudy. 1996. The WRPW motif of the Hairy-related basic helix-loop-helix repressor proteins acts as a 4-amino-acid transcription repression and proteinprotein interaction domain. Mol. Cell. Biol. 16: 2670-2677.

Gerwin, N., A. La Rosee, F. Sauer, H.P. Halbritter, M. Neumann, H. Jackle, and U. N auber. 1994. Functional and conserved domains of the Drosophila transcription factor encoded by the segmentation gene knirps. Mol. Cell. Biol. 14: 7899-7908.

Gray, S. and M. Levine. 1996a. Short-range transcriptional re pressors mediate both quenching and direct repression within complex loci in Drosophila. Genes \& Dev. 10: 700710.

1996b. Transcriptional repression in devel opment. Curr.
Opin. Cell Biol. 8: 358-364.

Gray, S., P. Szymanski, and M. Levine. 1994. Short-range repression permits multiple enhancers to function autonomously within a complex promoter. Genes \& Dev. 8: 1829-1838.

Gutjahr, T., E. Frei, C. Spicer, S. Baumgartner, R.A. White, and M. N oll. 1995. The Polycomb-group gene, extra sex combs, encodes a nuclear member of the WD-40 repeat family. EMBO J. 14: 4296-4306.

Han, K. and J.L. Manley. 1993a. Transcriptional repression by the Drosophila even-skipped protein: Definition of a minimal repression domain. Genes \& Dev. 7: 491-503.

-_- 1993b. Functional domains of the Drosophila Engrailed protein. EMBO J. 12: 2723-2733.

Hanna-Rose, W. and U. Hansen. 1996. Active repression mechanisms of eukaryotic transcription repressors. Trends Genet. 12: 229-234.

Harding, K., C. Rushlow, H.J. Doyle, T. Hoey, and M. Levine. 1986. Cross regulatory interactions among pair-rule genes in Drosophila. Science 233: 953-959.

Hartley, D.A., A. Preiss, and S. Artavanis-Tsakonas. 1988. A deduced gene product from the Drosophila neurogenic locus, Enhancer-of-split, shows homology to mammalian G-protein beta subunit. Cell 55: 785-795.

Heinzel, T., R.M. Lavinsky, T.M. Mullen, M. Soderstrom, C.D. Laherty, J. Torchia, W.M. Yang, G. Brard, S.D. N go, J.R. Davie, E. Seto, R.N. Eisenman, D.W. Rose, C.K. Glass, and M.G. Rosenfeld. 1997. A complex containing N-CoR, M sin3 and histone deacetylase mediates transcriptional repression. Nature 387: 43-48.

Heitzler, P., M. Bourouis, L. Ruel, C. Carteret, and P. Simpson. 1996. Genes of the Enhancer of split and Achaete-Scute complexes are required for a regulatory loop between $\mathrm{N}$ otch and Delta during lateral signaling in Drosophila. Development 122: 161-171.

Horlein, A.J., A.M. Naar, T. Heinzel, J. Torchia, B. Gloss, R. Kurokawa, A. Ryan, Y. Kamei, M. Soderstrom, C.K. Glass, and M.G. Rosenfeld. 1995. Ligand-independent repression by the thyroid hormone receptor mediated by a nuclear receptor co-repressor. Nature 377: 397-404.

Howard, K. and P. Ingham. 1986. Regulatory interactions between the segmentation genes fushi tarazu, hairy and engrailed in the Drosophila blastoderm. Cell 44: 949-957.

Ip, Y.T. and K. Hemavathy. 1997. Drosophila developmentdelimiting patterns by repression. Curr. Biol. 7: R216-R218.

Ish-H orowicz, D. and S.M. Pinchin. 1987. Pattern abnormalities induced by ectopic expression of the Drosophila gene hairy are associated with repression of fushi tarazu transcription. Cell 51: 405-415.

Jaynes, J.B. and P.H. O'Farrell. 1991. Active repression of transcription by the engrailed homeodomain protein. EMBO J. 10: 1427-1433.

Jiménez, G., S.M. Pinchin, and D. Ish-Horowicz. 1996. In vivo interactions of the Drosophila Hairy and Runt transcriptional repressors with target promoters. EMBO J. 15: 70887098.

John, A., S.T. Smith, and J.B. Jaynes. 1995. Inserting the ftz homeodomain into engrailed creates a dominant transcriptional repressor that specifically turns off ftz target genes in vivo. Development 121: 1801-1813.

Johnson, A.D. 1995. The price of repression. Cell 81: 655-658.

Keleher, C.A., M.J. Redd, J. Schultz, M. Carlson, and A.D. Johnson. 1992. Ssn6-Tup1 is a general repressor of transcription in yeast. Cell 68: 709-719.

Keyes, L.N., T.W. Cline, and P. Schedl. 1992. The primary sex determination signal of Drosophila acts at the level of transcription. Cell 68: 933-943. 
Klämbt, C., E. Knust, K. Tietze, and J.A. Campos-Ortega. 1989. Closely related transcripts encoded by the neurogenic gene complex Enhancer of split of Drosophila melanogaster. EMBO J. 8: 203-210.

Klingler, M. and J.P. Gergen. 1993. Regulation of runt transcription by Drosophila segmentation genes. Mech. Dev. 43: 319.

Knust, E., H. Schrons, F. Grawe, and J.A. Campos-Ortega. 1992. Seven genes of the Enhancer of split complex of Drosophila melanogaster encode helix-loop-helix proteins. Genetics 132: 505-518.

Kokubo, T., D.W. Gong, S. Yamashita, R. Takada, R.G. Roeder, M. Horikoshi, and Y. Nakatani. 1993. Molecular cloning, expression, and characterization of the Drosophila 85-kilodalton TFIID subunit. Mol. Cell Biol. 13: 7859-7863.

Kurokawa, R., M. Soderstrom, A. Horlein, S. Halachmi, M. Brown, M.G. Rosenfeld, and C.K. Glass. 1995. Polarity-specific activities of retinoic acid receptors determined by a co-repressor. Nature 377: 451-454.

Licht, J.D., W. Hanna-Rose, J.C. Reddy, M.A. English, M. Ro, M. Grossel, R. Shaknovich, and U. Hansen. 1994. Mapping and mutagenesis of the amino-terminal transcriptional repression domain of the Drosophila Krüppel protein. Mol. Cell Biol. 14: 4057-4066.

Martinez Arias, A. 1993. Development and patterning of the Iarval epidermis of Drosophila. In The development of Drosophila mel anogaster (ed. M. Bate and A. M artinez Arias), pp. 517-608. Cold Spring Harbor Laboratory Press, Cold Spring Harbor, NY.

N eer, E.J., C.J. Schmidt, R. N ambudripad, and T.F. Smith. 1994. The ancient regulatory-protein family of WD-repeat proteins. Nature 371: 297-300.

Parkhurst, S.M . and P.M. Meneely. 1994. Sex determination and dosage compensation: Lessons from flies and worms. Science 264: 924-932.

Parkhurst, S.M., D. Bopp, and D. Ish-Horowicz. 1990. X:A ratio, the primary sex determining signal in Drosophila, is transduced by helix-loop-helix proteins. Cell 63: 1179-1191.

Paroush, Z., R.L.J. Finley, T. Kidd, S.M. Wainwright, P.W. Ingham, R. Brent, and D. Ish-Horowicz. 1994. Groucho is re quired for Drosophila neurogenesis, segmentation and sexdetermination, and interacts directly with Hairy-related bHLH proteins. Cell 79: 805-815.

Paroush, Z., S.M. Wainwright, and D. Ish-Horowicz. 1997. Torso signalling regulates terminal patterning in Drosophila by antagonising Groucho-mediated repression. Development 124: 3827-3834.

Patel, N.H., E. Martin-Bianco, K.G. Coleman, S.J. Poole, M.C. Ellis, T.B. Kornberg, and C.S. Goodman. 1989. Expression of engrailed protein in arthropods, annelids and chordates. Cell 58: 955-968.

Pazin, M.J. and J.T. Kadonaga. 1997. SWI2/SNF2 and related proteins-ATP-driven motors that disrupt protein-DNA interactions. Cell 88: 737-740.

Pirrotta, V. 1988. Vectors for P-mediated transformation in Drosophila. In Vectors, a survey of molecular cloning vectors and their uses (ed. R.L. Rodriquez and D.T. Denhardt), pp. 437-456. Butterworth, Boston, MA.

Preiss, A., D.A. Hartley, and S. Artavanis-Tsakonas. 1988. The molecular genetics of Enhancer of split, a gene required for embryonic neural development in Drosophila. EMBO J. 7: 3917-3927.

Rushlow, C.A., A. Hogan, S.M. Pinchin, K.R. Howe, M.T. Lardelli, and D. Ish-Horowicz. 1989. The Drosophila hairy protein acts in both segmentation and bristle patterning and shows homology to N-myc. EMBO J. 8: 3095-3103.
Sambrook, J., E.F. Fritsch, and T. Maniatis. 1989. Molecular cloning: A laboratory manual. Cold Spring Harbor Laboratory Press, Cold Spring Harbor, NY.

Sanicola, M., J. Sekelsky, S. Elson, and W.M. Gelbart. 1995. Drawing a stripe in Drosophila imaginal disks: Negative regulation of decapentaplegic and patched expression by engrailed. Genetics 139: 745-756.

Sathe, S.S. and P.J. Harte. 1995. The Drosophila Extra sex combs protein contains WD motifs essential for its function as a repressor of homeotic genes. Mech. Dev. 52: 77-87.

Sauer, F., J.D. Fondell, Y. Ohkuma, R.G. Roeder, and H. Jäckle. 1995. Control of transcription by Kruppel through interactions with TFIIB and TFIIE beta. Nature 375: 162-164.

Schrons, H., E. Knust, and J.A. Campos-Ortega. 1992. The Enhancer of split complex and adjacent genes in the $96 \mathrm{~F}$ region of Drosophila melanogaster are required for segregation of neural and epidermal progenitor cells. Genetics 132: 481503.

Schwartz, C., J. Locke, C. Nishida, and T.B. Kornberg. 1995. Analysis of cubitus interruptus regulation in Drosophila embryos and imaginal disks. Development 121: 1625-1635.

Shepard, S.B., S.A. Broverman, and M. Muskavitch. 1989. A tripartite interaction among alleles of Notch, Delta, and Enhancer-of-split during imaginal development of Drosophila melanogaster. Genetics 122: 429-438.

Simon, J., D. Bornemann, K. Lunde, and C. Schwartz. 1995. The extra sex combs product contains WD 40 repeats and its time of action implies a role distinct from other Polycomb group products. Mech. Dev. 53: 197-208.

Smith, D. and K. Johnston. 1988. Single-step purification of polypeptides expressed in E. coli as fusions with glutathione S-transferase. Gene 76: 31-40.

Smith, S.T. and J.B. Jaynes. 1996. A conserved region of Engrailed, shared among all En-, Gsc-, Nk1-, Nk2- and Mshclass homeoproteins, mediates active transcriptional repression in vivo. Development 122: 3141-3150.

Sondek, J., A. Bohm, D.G. Lambright, H.E. Hamm, and P.B. Sigler. 1996. Crystal structure of a G-protein $\beta \gamma$ dimer at 2.1A resolution. Nature 379: 369-374.

Spradling, A.C. 1986. P element-mediated transformation. In Drosophila: A practical approach (ed. D.B. Roberts), pp. 175197. IRL Press, Oxford, UK.

Steller, H. and V. Pirrotta. 1985. A transposable P vector that confers G418 resistance to Drosophila Iarvae. EMBO J. 4: $167-171$.

Tautz, D. and C. Pfeifle. 1989. A non-radioactive in situ hybridization method for the localization of specific RN As in Drosophila embryos reveals translational control of the segmentation gene hunchback. Chromosoma 98: 81-85.

Treitel, M.A. and M. Carlson. 1995. Repression by SSN 6-TUP1 is directed by MIG1, a repressor/activator protein. Proc. Natl. Acad. Sci. 92: 3132-3136.

Um, M., C. Li, and J.L. Manley. 1995. The transcriptional repressor Even-skipped interacts directly with TATA-binding protein. Mol. Cell. Biol. 15: 5007-5016.

Verrijzer, C.P. and R. Tjian. 1996. TAFs mediate transcriptional activation and promoter selectivity. Trends Biochem. Sci. 21: 338-342.

Wall, M .A., D.E. Coleman, E. Lee, J.A. Iñiguez-Lluhi, B.A. Posner, A.G. Gilman, and S.R. Sprang. 1996. The structure of the G protein heterotrimer: Gi $\alpha 1 \beta 1 \gamma 2$. Cell 83: 1047-1058.

Wolffe, A.P. 1997. Sinful repression. Nature 387: 16-17.

Y ounger-Shepherd, S., H. Vässin, E. Bier, L.Y. Jan, and Y.N. Jan. 1992. deadpan, an essential pan-neural gene encoding an HLH protein, acts as a denominator in Drosophila sex determination. Cell 70: 911-922. 


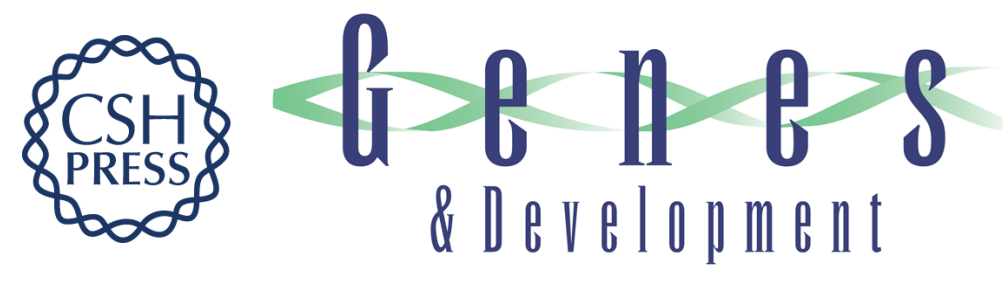

\section{Groucho acts as a corepressor for a subset of negative regulators, including Hairy and Engrailed}

Gerardo Jiménez, Ze'ev Paroush and David Ish-Horowicz

Genes Dev. 1997, 11:

Access the most recent version at doi:10.1101/gad.11.22.3072

References

This article cites 79 articles, 37 of which can be accessed free at: http://genesdev.cshlp.org/content/11/22/3072.full.html\#ref-list-1

\section{License}

Email Alerting

Receive free email alerts when new articles cite this article - sign up in the box at the top Service right corner of the article or click here.

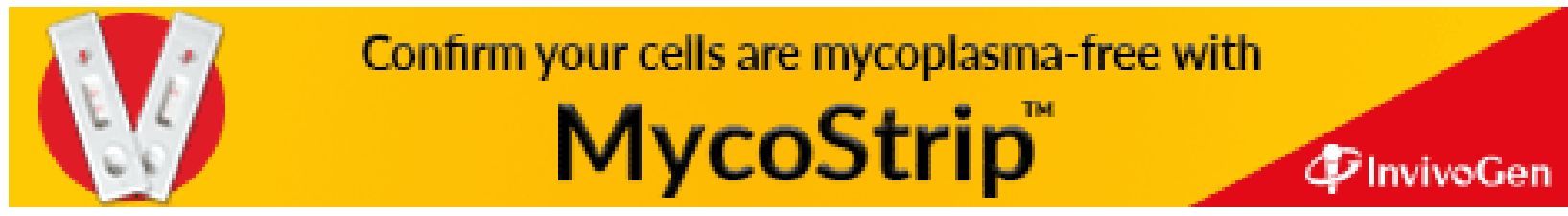

